\title{
Study on Different Extraction Methods and Antimicrobial Potential of Citrus Peel and Leaf
}

\author{
Mohit Roop Rai, Ritik Chawla and Anis Mirza** \\ Department of Horticulture, School of Agriculture, Lovely Professional University, \\ Punjab, India \\ *Corresponding author
}

\section{A B S T R A C T}

\begin{tabular}{|l|}
\hline K e y w o r d s \\
Limonene, \\
Anticancer, \\
Antitumor, \\
Naringenin \\
\hline Article Info \\
\hline $\begin{array}{l}\text { Accepted: } \\
\text { 04 October } 2020 \\
\text { Available Online: } \\
10 \text { November } 2020\end{array}$ \\
\hline
\end{tabular}

\section{Introduction}

Citrus is the world's most valuable group of fruits which are commercially produced and anywhere the environment is acceptable. It is commonly cultivated in many areas with sufficient tropical, subtropical and temperate climatic conditions. The Citrus genus belongs to the Citrineae subtribe, sub-family Aurantioideae of the family Rutaceae. The other economically important genera of this family are Poncirus and Fortunella. India, a natural home of many species of citrus harbours vast reservoir of diverse types and forms ranging from oranges, mandarins, pummelo, grapefruit, lime and lemon, wild and semi wild species and other related genera.

Citrus species are also used as a medicinal plant. Like Citrus limon is mainly used for its anti-cancer and anti-bacterial activity alkaloids in crude extracts of different sections (stem, leaves, juice, flower and peel) against clinically significant bacterial strains (Kawaii et al., 2000). The limonoids were derived from $C$. limon or exhibit strong antifungal and antibacterial activity. Citrus fruit extracts are among the most commonly studied therapeutic agents (e.g. grape fruit, limon and orange) for food applications and have shown an important decrease in bacterial 
growth (Corbo et al., 2008). There are many Citrus sp. of these $C$. paradise (grape fruit), C. limetta (sweet lemon), C. aurantium (bitter orange), $C$. jambhiri (Rough lemon) and $C$. limon (lemon) (Tawfik et al., 2010). Despite this vast cultivation, phylogeny and taxonomy of many citrus varieties remain uncertain which has been complicated by several factors such as hybridization, apomixis, polyploidy and bud mutations.

An antimicrobial is a substance which kills the microbes (i.e. fungi, protozoa, bacteria or viruses) and also inhibits their growth. Antibiotics are those substances which are formed by microorganisms and destroy or block other microorganisms from growing. Some Indian herbal oils have antimicrobial properties to investigate the properties for use as botanical protection in food industries. Lime exocarp comprises $7 \%$ of all the usual volatile essential oils, the main components of which are citral, fenchone, B-pinene and limonene. Major fraction of peel oil includes esquiterpenes, monoterpenes (76\%) and oxygen containing compounds like alcohols, aldehydes and esters. Citrus contains unique forms of phenolic compounds such as flavonoids, which are considered to exhibit antiviral, anti-oxidant, anti-allergenic, anticarcinogenic, anti-inflammatory, antimicrobial activity (Escobedo-Avellaneda et al., 2014). Citrus flavonoids have a wide range of biological activity including antidiabetic, anticancer, antibacterial, and antiviral antifungal activities (Burt, 2004; Ortuño et al., 2006). Antimicrobial study was performed to detect antimicrobial property of the different extracts of leaves, peel in methanol and tertra cycline and streptomycin (1mg / ml) levels against E.coli were calculated using the agar plate diffusion process.

In their peels, the citrus contain essential oils which were extracted by the hydrodistillation process. Alpha-pinene, m-cymene, sabinene, 4-terpineol, d-limonene, linalool, B-myrcene and B-pinene were the key components of the oils extracted. Among the all the most important component was D-limonin (6693\%). The highest antimicrobial activity of bacteria was found ( $S$. typhimurium, $B$. cereus, E. coli, $S$. aureus etc) with essential oil of the blood orange (C.sinsesis).

Antimicrobial impact of aqueous juice and peel extract from dried and fresh citrus and sweet lemon against 6 gram +ve and 8 gram ve bacteria or yeast isolates like Entenococcus faecalis.

Antimicrobial effect of aqueous extract of juice and peel from dried and fresh citrus and sweet lemon against 8 gram -ve and 6 gram +ve bacteria and yeast isolates including Entenococcus faecalis, Enterobacteraeroge, Staphylococcus pneumoniae, Staphylococcus pyogenes, Staphylococcus agalactiae, $S$. aureus, Pseudomonas aeruginosa etc. Antimicrobials and antibiotics from plant sources have been shown to function more effectively with less side-effects and additional beneficial effects (Akhilesh et al., 2012). Commonly bacteria have a genetic capacity to spread and develop tolerance to drugs used as therapeutic agents (Nascimento et al., 2000). In therapeutic therapies use of plant extracts and phytochemicals with both known antimicrobial properties may play a major role (Prabuseenivasan et al., 2006).

\section{Plant parts used}

Peel: Although the peel of citrus is bitter in taste if it is eaten as a raw but it also play a major role in making of marmalade or other soups. Peel is the protective outer covering or outer skin of the fruit. Botanically it is also called as exocarp. Fruit type like Hesperidium contains very thick type peel. In citrus species the inner and outer part peeled off together 
and after combining both the parts it is called as peel. The layer which is the juicy part of the fruit is called endocarp. In some of the fruits like apple, pear the peel can be eaten with fruit while fruits like grapefruit, pomegranate and banana the peel should have to be removed before eating of the fruit. In fruit about $25-30 \%$ area covered by the peel and it is wasted by almost everyone. The citrus peel byproduct contains high amount of antioxidants and antimicrobial compounds these can be used as an antioxidant agents or phytochemicals. The wasted peel of citrus contains wide range of biological activities like antiviral, antibacterial, antidiabetic, anticancer, antifungal etc. The citrus peel generally contains two types of layers, the outermost layer of the peel is called zest and it is made up from citral (5\%) and limonene (90\%). By proper management of the peel we can decrease the level of solid waste and also helps in adding value for this after cutting the outer layer of the peel which is called as zest. Now-a-days it is used as a flavoring agent in biscuits, pies, candies, cakes or chocolates.

Citrus peel is very good source of nutrients as it contains phytochemicals and these are Ysitosterol, B-sitosterol, glycosides and volatile oils. Certain flavones, phenolic compounds and ascorbic acid contains special activities. The peel is used against digestion, peptic, ulcer, scurvy, eye infections, respiratory disorders, gums, piles, skin care, weight loss etc (Ali et al., 2017).

John et al., (2017) was conducting an experiment for evaluating the antioxidant and antimicrobial properties from the peel of citrus lemon. They collected the fresh lemons from the Chennai local market and removed the peel of lemon after washing it and kept it for 4-5 days at room temperature. After that they pulverized the dried peel using an electric blender and used it for methanol and acetone methods of extraction.
Leaf: Citrus leaves are generally compound which varies from trifoliate (poncirus trifoliate) to palmately compound (e.g. Casimiora spp.) to pinnately compound (e.g. Citropsis gilletaiana). During the time of full sun, the leaves of citrus spp. become strongly conduplicate while in case of shady conditions the leaves are more or very less conduplicate.

The leaf of the citrus is a rich source of the antimicrobial properties which show susceptibility against certain bacteria like Escherichia coli, Salmonella typhi and Staphylococcus aureus. The leaves of the citrus also contain essential oils. Saeb et al.,(2016) were collected fresh leaves of citrus and used for the extraction of antimicrobial activities against the bacteria (Escherichia coli, S. aureus, Bacillus subtilis, Salmonella typhi). They were used the shade drying method for drying of leaves at room temperature for 72 hours and used the powdered form of leaves with $80 \%$ methanol. They were used three different species of citrus ( $C$. grandis, $C$. reticulata and C.limon).

\section{Ethyl alcohol extract}

Ethanol is the one of the important organic compound. It is called by different names (like ethyl alcohol, drinking alcohol, simple alcohol, grain alcohol and spirit) having chemical formula $\left(\mathrm{C}_{2} \mathrm{H}_{6} \mathrm{O}\right)$. It is flammable, volatile colorless liquid having a characteristic odor. Ethanol is used in wide range of industries. It is used in making antiseptic, hand sanitizer liquid used against the bacteria. Ethanol plays a major role for extracting the antimicrobial potential from the different parts of the citrus species. Various scientists used ethanol method of extraction with the parts of citrus like peel, seed and leaf. EL-Desoukey (2018) conducted an experiment for evaluating the antimicrobial effect of orange. They were used $10 \mathrm{ml}$ of 
ethanol as a solvent with $5 \mathrm{~g}$ of dried plant peel for the extraction. After the extraction it is used against various bacterial strains. Different scientists used different concentration of ethanol. Yashaswini and Arvind (2018) were used $4 \mathrm{~g}$ of orange peel with $20 \mathrm{ml}$ of ethanol for the extraction of antimicrobial properties of orange (Citrus reticulata). Pandey Amit et al., (2011) were used $70 \%$ ethanol as a solvent for the extraction of antimicrobial properties from the peel of citrus limon. Ahmad and Ahmad, (2016) were conducting an experiment for evaluating the antibacterial activity of citrus limon. They were used $250 \mathrm{ml}$ of ethanol $(95 \% \mathrm{v} / \mathrm{v})$ solvent with $25 \mathrm{~g}$ dried powdered leaves.

\section{Extract of methanol}

Methanol also called by other name methyl alcohol having the chemical formula $\mathrm{CH}_{3} \mathrm{OH}$. It is a volatile, flammable, colorless, light liquid with odor similar to ethanol. Methanol acts as a major solvent for the extraction of antimicrobial, antibacterial or antifungal properties from the citrus species. Dhanavade et al., (2011) were conducting an experiment for evaluating the antimicrobial activity of lemon (Citrus lemon L.) from the peel. They used the methanol solvent for the method of extraction. Saeb et al., (2016) were used $80 \%$ methanol as a solvent agent with the shade dried leaf powder of citrus limon, Citrus reticulata and Citrus grandis for evaluating the antibacterial activities against some of the pathogenic bacteria. Yashaswini and arvind, (2018) were used the $20 \mathrm{ml}$ of methanol solvent with $4 \mathrm{~g}$ of orange peel powder used for the extraction method of antimicrobial properties. Abd et al., (2016) were conducting an experiment for finding the antioxidant properties from the peel of orange and lemon. They used the $80 \mathrm{ml}$ of methanol $(80 \%)$ with $10 \mathrm{~g}$ dried peel powder and after kept at room temperature the extract were centrifuged at
$5000 \mathrm{rpm}$ for $30 \mathrm{~min}$ at room temperature. They were filtered by using Whatman no. 4 filter paper.

\section{Aqueous extract}

It is one of the easy and important methods of extraction for evaluating the antimicrobial properties from the different parts of the citrus species. Different scientists use this aqueous method of extraction with different quantity of the aqueous. EL-Desoukey (2018) were used this method. They were added the dry peel of citrus into the boiled distilled water and kept at $4{ }^{\circ} \mathrm{C}$. Amengialue et al., (2016) were used the $90 \mathrm{ml}$ of distilled water in $10 \mathrm{~g}$ powder of peel. After that they were cover it with aluminium foil and filter the product before use. Ahmad and Ahmad et al., (2016) were used this method of extraction for evaluating the antibacterial activity of citrus species. They used $25 \mathrm{~g}$ of dried powdered with hot distilled water and boiled the matter for $30 \mathrm{~min}$. This aqueous method plays a major role in evaluating the antibacterial and antimicrobial potential of citrus limon.

\section{Extract of acetone}

Acetone is called propanone, it is an organic compound having chemical formula $\left(\mathrm{CH}_{3}\right)_{2} \mathrm{CO}$. It is highly volatile, flammable or colorless liquid having a pungent odor. It has various benefits many scientists used it for the antimicrobial properties extraction method. Dhanavade et al., (2011) were used acetone at their experiment for evaluating the antimicrobial activity of citrus lemon peel and check their impact on different bacterial pathogens. Ahmad and Ahmad, (2016) were used acetone solvent at $95 \% \quad(\mathrm{v} / \mathrm{v})$ concentration with the dried powder of leaves. They used $250 \mathrm{ml}$ of solvent acetone with $25 \mathrm{~g}$ powder. Yashaswini and Arvind, (2018) used the $4 \mathrm{~g}$ of dry orange powdered from peel and after that stored at $4{ }^{\circ} \mathrm{C}$ and treat with $20 \mathrm{ml}$ of acetone extract. They incubate the mixture at 
$130 \mathrm{rpm}$ for 36 hours at $30^{\circ} \mathrm{C}$ for the successful extraction of the antimicrobial properties of the (Citrus reticulata var. kinnow) and were used it against the pathogenic like Staphylococcus aureus, Klebsiella pneumoniae, Escherichia coli and Pseudomonas aeruginosa.

\section{Antimicrobial properties of citrus}

Abdet al., (2016) had isolated various antimicrobial and chemical properties of lemon and orange peel. They were used the extract of ethanolic and methanolic of the dried peel (air oven drying methods or microwave). Ahmad and Ahmad, (2016) had isolated the antibacterial activity of Citrus limon and Morus nigra. They used ethyl acetate and acetone extract from Citrus limon and Morus nigra. Agar well diffusion method for bacterial pathogens (Bacillus and Staphylococcus aureus) had been used to evaluate anti-bacterial behaviour. Akinnibosun et al., (2015) were demonstrated the antimicrobial potential from the leaf extract of the Citrus aurantifolia, Bryophyllum pinnatum $L$. The agar well diffusion method is used to test the various organisms like Staphylococcus aureus, Penicillium notatum, Escherichia coli, Pseudomonas aeruginosa, Klebsiella pneumonia, Mucormucedo, Aspergillus niger and Candida albicans. The result shows that the $B$. pinnatum was less effective compared to the extract of $C$. aurantifolia against the organisms. Aladekoyi et al., (2016) was worked on the antimicrobial properties which were extracted from the seeds of three Citrus sp. (Citrus aurantifolia, Citrus limon, and Citrus aurantium). By using the method of agar well diffusion against different bacterial pathogens, they had isolated the antimicrobial properties. They also said that the oils which were extracted from citrus seeds are used in perfumery industries, confectionary and toiletry. Oils which were extracted from the seeds of the bitter lemon show very high inhibition against Klebsiella, against proteins and against the E. coli. Ali et al., (2017) had evaluated the activity of antimicrobial of methanolic extract from Citrus limon peel. The methanolic extract from the peel was separated from fruits, shade dried and powdered using methanol. These extracts are using against the one fungal strain (Candida albicans) two bacterial strains among and other gram +ve (S.aureus) and gram -ve (Escherichia coli) using agar well diffusion method. It results that the Citrus limon peel contains high amount of phytochemicals. Amengialue et al., (2016) has responded for the phytochemical and antimicrobial properties of citrus lemon. These antimicrobial properties were evaluated against some fungi and bacterial pathogens like Bacillus subtillis, Staphylococcus aureus, Fusarium oxysporum, Pseudomonas, Aspergillus niger. The isolation done from the seed and peels by using ethanol and methanol extraction methods.

Citrus is a rich source of essential oils which consist of D-dimonene. Bozkurt et al., (2017) was extracted the essential oils from different species of citrus fruit peels like lemon $(C$. limon), orange $(C$. sinensis), mandarin $(C$. reticulate), grapefruit ( $C$. paradise). These essential oils are used to assess the antimicrobial activity of a variety of bacteria and to know the various elements of essential oils by GC-MS. Citrus fruit peel contains flavonones and polymethoxylated flavones in good amount which are also present in other plants. Dhanavade et al., (2011) studied the antimicrobial function of the lemon. They also tested MLC antimicrobial activity with various solvents against micro-organisms such as Pseudomonas aeruginosa. ElDesoukey, (2018) were studied about the antimicrobial effect of Citrus sinensis (orange) peel. These antimicrobial activities were tested against the pathogens isolated from poultry or animals (Pseudomonas aerogenes, Bacillus cereus, Escherichia coli, 
Staphylococcus aureus and Candida albican). The method used for isolation was Agar well diffusion method. The results observed that the peel of Citrus sinensis (orange) contains Tannins, alkaloids, saponins, flavonoids. Their antibacterial effect act against the Gram +ve and Gram -ve bacteria. Ewansiha, (2020) in his experiment found antibacterial activity of Citrus Limon juice against the pathogenic organisms. He used column chromatography and cold pressing extraction method to obtain the crude juice extracts. Over Streptococcus Pyogenes, Klebsiella pneumoniae and Salmonella enterica he used other processes such as Agar well diffusion and tube dilution. The peel of citrus waste from various industries is a good source of polyphenols. Hegde et al., (2015) were isolates the different polyphenols from the orange fruit by using different drying technique.

Hindi and chabuck, (2013) were isolate the antimicrobial properties of citrus from their aqueous extract like from peel or juice against 8 Gram -ve bacteria and $6 \mathrm{Gram}+\mathrm{ve}$ bacteria. For this, they used agar well diffusion method. John et al., (2017) was evaluated the antioxidant and antimicrobial efficiency of citrus lemon $(C$. limon L.) from the peel. The method used for determining the antimicrobial potential was DPPH assay, FRAP and Phospho molybdenum assay and these were tested against four bacterial strains. Kaur, (2014) has responds to determine phenolics from Kinnow peel and also for antimicrobial properties. The effects of various solvents like (Methanol, Ethanol, Ethyl acetate, Isopropyl alcohol, Dichloro methane) for the extraction of phenolics were studied. The extraction for this drop done by two methods i.e. Soxhlet and conventional extraction method. She also said that the Hesperidium which is dominant in flavonone was isolated and investigated for antimicrobial properties. Kumari et al., (2016) was performed an experiment to determine the antimicrobial properties from leaf (young and mature), peel in methanol and tetracycline and streptomycin $(1 \mathrm{mg} / \mathrm{ml})$ levels against E.coli were calculated using the agar plate diffusion process. Yashaswini and Arvind, (2018) was determined the antimicrobial properties and phenolic content of the orange (Kinnow) against the pathogenic bacteria Pseudomonas aeruginosa, Escherichia coli, Klebsiella pneumoniae and Staphylococcus. For evaluating the antimicrobial potential Agar well diffusion method was used. Pandey et al., (2011) has demonstrated the phytochemical and antimicrobial activity from the seed and peels of Citrus limon. The analysis was done by using the agar well diffusion method. And these properties were tested against the fungal and bacterial pathogens (S. aureus, P. aeruginosa, E. coli).

Halima and Allem, (2016) worked together on evaluating the antimicrobial property of algerian lemon (Citrus limon L.). They were isolated these properties from the peel and citrus limon seeds and also use disk diffusion method against six pathogenic bacteria and fungal strain. The result of this experiment teaches us that both peel and seeds of Citrus contain quercentin, a flavonoid which is a very good antimicrobial property. Saeb et al., (2016) was studied to determine the antimicrobial properties present in the three species of the citrus against the pathogenic bacteria. The three species of citrus were Citrus grandis, C. limon, C. reticulata. They worked on the antimicrobial effects from leaf extract and other essential oils of the citrus species. They were using the three citrus species against S.aureus, Bacillus subtilis, Escherichia coli and Salmonella typhimurium by using E- test and agar disc diffusion method. Safdar et al., (2017) conducted a maceration and ultrasound extraction test to extract polyphenols from Kinnow peel (Citrus reticulata). The antimicrobial properties of various polyphenols were extracted by using 
ferric reducing antioxidant power (FRAP) and these properties were used against the different strains of Staphylococcus aurens, Bacillus cereus and salmonella typhimurium. Shetty et al., (2016) worked for evaluating the in-vitro antimicrobial potential from the extract of Citrus sinensis peel. The method used for checking the antimicrobial activity was agar well diffusion method and their activity checked against Streptococcus mutans and Lactobacillus acidophilus.

In conclusion the citrus peel, leaf and seed which are wasted by the peoples and industries are rich source of the antimicrobial properties and having numerous therapeutic properties like anticancer, antiviral, antiinflammatory activities. High amount of phyto-chemical and bio-active compounds like carotenoids, minerals, flavonoids and vitamins present in citrus fruit. Various methods of extraction were used like Hydrodistillation method, GC/MS analysis, Agar well diffusion method, Ethyl alcohol extract, Methanol extract, Aqueous extract, Acetone extract etc.

\section{References}

Abd El-ghfar, M. A., Ibrahim, H. M., Hassan, I. M., Fattah, A. A., and Mahmoud, M. H. (2016). Peels of lemon and orange as value-added ingredients: chemical and antioxidant properties. Int. J. Curr. Microbiol. App. Sci, 5(12), 777-794.

Ahmad, R., and Ahmed, A. (2016). Evaluation of antibacterial activity of Morusnigra and Citrus limon. Journal of Ayurvedic and Herbal Medicine, 2(6), 213-217.

Akhilesh, K., Raghvendra, P. S., Vikas, G., and Madhulika, S. (2012). Antimicrobial properties of peels of citrus fruits. International Journal of Universal Pharmacy and Life Science, 2, 24-38.
Akinnibosun, F. I., and Edionwe, O. (2015). Evaluation of the Phytochemical and Antimicrobial potential of the Leaf Extracts of Bryophyllum pinnatum L. and Citrus aurantifolia Sw. and their Synergy. Journal of Applied Sciences and Environmental Management, 19(4), 611-619.

Aladekoyi, G., Omosuli, S. V., Orungbemi, O. O., and Adesuyi, A. T. (2016). Evaluation of antimicrobial activity of oil extracted from three different citrus seeds (Citrus limon, Citrus aurantifolia and Citrus aurantium). Int. J. Sci. Res. Eng. Stud, 3(3), 16-20.

Ali, J., Das, B., and Saikia, T. R. I. D. E. E. P. (2017). Antimicrobial activity of lemon peel (Citrus limon) extract. International Journal of Current Pharmaceutical Research, 9(4), 79-81.

Amengialue, O. O., Oviasogie, E. F., Omoigberale, M. N. O., Omoregie, B. O., and Okoro, T. C. (2016). Evaluation of Antimicrobial Potential And Phytochemical Screening Of Citrus Lemon. European Journal of Advanced Research in Biological and Life Sciences Vol, 4(2).

Bozkurt, T., Gülnaz, O., and Kaçar, Y. A. (2017). Chemical composition of the essential oils from some citrus species and evaluation of the antimicrobial activity. IOSR $J$ Environ SciToxicol Food Technol, 11, 1-8.

Burt, S. (2004). Essential oils: their antibacterial properties and potential applications in foods - a review. International journal of food microbiology, 94(3), 223-253.

Corbo, M. R., Speranza, B., Filippone, A., Granatiero, S., Conte, A., Sinigaglia, M., and Del Nobile, M. A. (2008). Study on the synergic effect of natural compounds on the microbial quality decay of packed fish 
hamburger. International Journal of Food Microbiology, 127(3), 261-267.

Dhanavade, M. J., Jalkute, C. B., Ghosh, J. S., and Sonawane, K. D. (2011). Study antimicrobial activity of lemon (Citrus lemon L.) peel extract. British Journal of pharmacology and Toxicology, 2(3), 119-122.

El-Desoukey, R. M. (2018). The Phytochemical and Antimicrobial Effect of Citrus sinensis (Orange) Peel Powder Extracts on Some Animal Pathogens as Eco-Friendly. EC Microbiology, 14, 312-318.

Escobedo-Avellaneda, Z., Gutiérrez-Uribe, J., Valdez-Fragoso, A., Torres, J. A., and Welti-Chanes, J. (2014). Phytochemicals and antioxidant activity of juice, flavedo, albedo and comminuted orange. Journal of Functional Foods, 6, 470-481.

Ewansiha, J. U. (2020). Evaluation of Antibacterial Potency of Citrus Limon (Lemon) Juice Against Some Pathogenic Organisms as Alternative Source of Chemotherapy. European Journal of Biology and Biotechnology, 1(1).

Hegde, P., Agrawal, P., and Gupta, P. K. (2015). Isolation and optimization of polyphenols from the peels of orange fruit. J. Chem. Pharm. Sci, 8(3), 149. 159.

Hindi, N. K. K., and Chabuck, Z. A. G. (2013). Antimicrobial activity of different aqueous lemon extracts. Journal of Applied Pharmaceutical Science, 3(6), 74.

John, S., Monica, S. J., Priyadarshini, S., Sivaraj, C., and Arumugam, P. (2017). Antioxidant and antimicrobial efficacy of lemon (Citrus limonum L.) Peel. Int. J. Pharm. Sci. Rev. Res, 46(1), 115-118.

Kaur, K. (2014).henolic compounds and flavonoids from kinnow peel and their microbial activity (Doctoral dissertation, Punjab Agricultural University Ludhiana).

Kawaii, S., Tomono, Y., Katase, E., Ogawa, K., Yano, M., Koizumi, M., and Furukawa, H. (2000). Quantitative study of flavonoids in leaves of Citrus plants. Journal of agricultural and food chemistry, 48(9), 3865-3871.

Kumari, S., Siddique, F. M. S., Gupta, S. D., and Baruah, A. (2016). Antimicrobial property of different parts of Citrus limon. IOSR Journal of Biotechnology and Biochemistry, 2(2), 53-55.

Nascimento, G. G., Locatelli, J., Freitas, P. C., and Silva, G. L. (2000). Antibacterial activity of plant extracts and phytochemicals on antibioticresistant bacteria. Brazilian journal of microbiology, 31(4), 247-256.

Ortuño, A., Báidez, A., Gómez, P., Arcas, M. C., Porras, I., García-Lidón, A., and Del Río, J. A. (2006). Citrus paradisi and Citrus sinensis flavonoids: Their influence in the defence mechanism against Penicillium digitatum. Food chemistry, 98(2), 351-358.

P.yashaswini and Arvind, " Antimicrobial properties of orange (Citrus reticulata var. kinnow) peel extracts against pathogenic bacteria, International journal of current microbiology and applied sciences, vol7 no.3 (2018).

Pandey, A., Kaushik, A., and Tiwari, S. K. (2011). Evaluation of antimicrobial activity and phytochemical analysis of Citrus limon.J Pharm Biomed Sci, 13(17), 1-7.

Prabuseenivasan, S., Jayakumar, M., and Ignacimuthu, S. (2006). In vitro antibacterial activity of some plant essential oils. BMC complementary and alternative medicine, 6(1), 39.

Halima-Mansour, S., and Allem, R (2016). Evaluation of antimicrobial activity of Algerian Lemon (Citrus limon v. Eureka) peels and juice extracts. 
Saeb, S., Amin, M., Gooybari, R. S., and Aghel, N. (2016). Evaluation of antibacterial activities of Citrus limon, Citrus reticulata, and Citrus grandis against pathogenic bacteria. International Journal of Enteric Pathogens, 4(4), 3-37103.

Safdar, M. N., Kausar, T., Jabbar, S., Mumtaz, A., Ahad, K., and Saddozai, A. A. (2017). Extraction and quantification of polyphenols from kinnow (Citrus reticulate L.) peel using ultrasound and maceration techniques. Journal of food and drug analysis, 25(3), 488-500.
Shetty, S. B., Mahin-Syed-Ismail, P., Varghese, S., Thomas-George, B., Kandathil-Thajuraj, P., Baby, D., and Devang-Divakar, D. (2016). Antimicrobial effects of Citrus sinensis peel extracts against dental caries bacteria: An in vitro study. Journal of clinical and experimental dentistry, 8(1), e71.

Tawfik, N. O., Al-Haliem, S. M., and Al-Ani, W. N. (2010). Evaluation of the antibacterial activity of citrus juices: an in vitro study. Al-Rafidain Dental Journal, 10(16), 376-382.

\section{How to cite this article:}

Mohit Roop Rai, Ritik Chawla and Anis Mirza. 2020. Study on Different Extraction Methods and Antimicrobial Potential of Citrus Peel and Leaf. Int.J.Curr.Microbiol.App.Sci. 9(11): 246254. doi: https://doi.org/10.20546/ijcmas.2020.911.029 